\title{
FIBER OPTIC EXPERIENCE WITH THE SMART ACTUATION SYSTEM ON THE F-18 SYSTEMS RESEARCH AIRCRAFT
}

\author{
Eddie Zavala \\ NASA Dryden Flight Research Center \\ P.O. Box 273 \\ Edwards, California 93523-0273
}

\begin{abstract}
High bandwidth, immunity to electromagnetic interference, and potential weight savings have led to the development of fiber optic technology for future aerospace vehicle systems. This technology has been incorporated in a new smart actuator as the primary communication interface. The use of fiber optics simplified system integration and significantly reduced wire count. Flight test results showed that fiber optics could be used in aircraft systems and identified critical areas of development of fly-bylight technology. This paper documents the fiber optic experience gained as a result of this program, and identifies general design considerations that could be used in a variety of specific applications of fiber optic technology. Environmental sensitivities of fiber optic system components that significantly contribute to optical power variation are discussed. Although a calibration procedure successfully minimized the effect of fiber optic sensitivities, more standardized calibration methods are needed to ensure system operation and reliability in future aerospace vehicle systems.
\end{abstract}

\section{NOMENCLATURE}

$\begin{array}{ll}\text { act } & \text { actuator } \\ \text { ch } & \text { channel } \\ \text { cmd } & \text { command } \\ \text { CCDL } & \text { cross-channel data link } \\ \text { DDV } & \text { direct drive valve } \\ \text { DFRC } & \text { Dryden Flight Research Center } \\ \text { DCI } & \text { Dynamic Controls Incorporated, } \\ & \text { Dayton, Ohio }\end{array}$

$\begin{array}{ll}\text { dB } & \text { decibels } \\ \text { EMI } & \text { electromagnetic interference } \\ \text { EPAD } & \text { electrically powered actuation design } \\ \text { FBL } & \text { fly-by-light } \\ \text { FCC } & \text { flight control computer } \\ \text { F.O. } & \text { fiber optic } \\ g & \text { normal acceleration (the standard } \\ & \quad \text { acceleration of gravity of } \\ \text { gm } & \text { grams } \\ \text { HIL } & \text { hardware-in-the-loop } \\ \text { IBIT } & \text { initiated built-in test } \\ \text { Ibox } & \text { interface box } \\ \text { I/O } & \text { input/output } \\ \text { L/H ail } & \text { left-hand aileron } \\ \text { LVDT } & \text { linear variable differential transformer } \\ \text { M } & \text { Mach number } \\ \text { mils } & \text { thousandths of a inch, } 0.001 \text { in. } \\ \text { NASA } & \text { National Aeronautics and Space } \\ & \text { Administration } \\ \text { pos } & \text { position } \\ \text { q } & \text { dynamic pressure, lb/ft }{ }^{2} \\ \text { ram } & \text { actuator cylinder position } \\ \text { RCVR } & \text { receiver } \\ \text { R/H ail } & \text { right-hand aileron } \\ \text { RT } & \text { remote terminal } \\ \text { rad } & \text { radians } \\ \text { SAct } & \text { smart actuator } \\ \text { SMA } & \text { subminiature A-type connector } \\ \text { SOV } & \text { solenoid-operated valve } \\ \text { SRA } & \text { Systems Research Aircraft } \\ & \end{array}$




\begin{tabular}{|c|c|}
\hline $\sec$ & seconds \\
\hline std & standard \\
\hline Vdc & Volts, dc \\
\hline WPAFB & $\begin{array}{l}\text { Wright Patterson Air Force Base, } \\
\text { Dayton, Ohio }\end{array}$ \\
\hline XMTR & transmitter \\
\hline$\alpha$ & angle of attack, deg \\
\hline$\mu \mathrm{W}$ & microwatts, one millionth of a watt \\
\hline $\begin{array}{l}\text { MIL-STD- } \\
1553\end{array}$ & $\begin{array}{l}\text { Digital Time Division Command/ } \\
\text { Response Multiplex Data Bus } \\
\text { (Military Standard) }\end{array}$ \\
\hline 1773 & $\begin{array}{l}\text { nonstandard fiber optic } \\
\text { mechanization of digital time } \\
\text { division command/response } \\
\text { multiplex data bus }\end{array}$ \\
\hline
\end{tabular}

\section{INTRODUCTION}

Development programs for fighter aircraft, as well as new large transport aircraft, have identified fiber optic technology as an integral component of future aircraft systems. Conventional fly-by-wire system configurations often require unique interfaces for each flight control surface actuator, which results in a large amount of wiring. Fiber optics has been considered for aerospace vehicle applications because it has high bandwidth capability, immunity to electromagnetic interference (EMI), and significant weight savings. Although fiber optics has been successfully used in the telecommunications industry, the application of this technology to aircraft systems has been limited.

The NASA Dryden Flight Research Center (DFRC), Edwards, California, became involved in fiber optics through the smart actuator program. The primary objective of this program was to demonstrate local closed-loop control of a flight control surface actuator using miniaturized smart electronics as an integral part of the actuator assembly. Because the actuator used fiber optics, a second objective was to determine the suitability of fiber optics for aircraft system architectures. The smart actuator development was a joint initiative by the Naval Air Warfare Center-Warminster, now located at Patuxent River, Maryland, and Wright Patterson Air Force Base (WPAFB), Dayton, Ohio. The actuator was designed to be a fit, form, and functional replacement of the F-18 aileron actuator, and was manufactured by HR Textron, Incorporated, Valencia, California.
The smart actuator was the first of three advanced actuators to be flight tested at the NASA DFRC as part of the Electrically Powered Actuation Design (EPAD) program. This flight test program was successful in demonstrating the feasibility of local closed-loop control of a surface actuator. However, a great deal of experience with fiber optics was also gained through system integration tests and environmental tests. This paper documents the lessons learned and the methods employed to ensure the operation of the fiber optic data links in the smart actuation system. In addition, general design considerations that could be used in a variety of specific applications of fiber optics are presented.

\section{SMART ACTUATOR DESIGN DESCRIPTION}

The smart actuator (fig. 1) was designed to satisfy the production F-18 aileron actuator operational requirements shown in table 1 . The actuator utilizes a simplex hydraulic supply and is designed to be a fit, form, and functional replacement of the standard F-18 aileron actuator. The actuator design incorporates a direct drive valve (DDV), and two independent electronic modules that perform servoloop control, fault monitoring, and redundancy management. Each electronic module is commanded by a separate channel of the aircraft flight control computers (FCCs). The operational modes of the

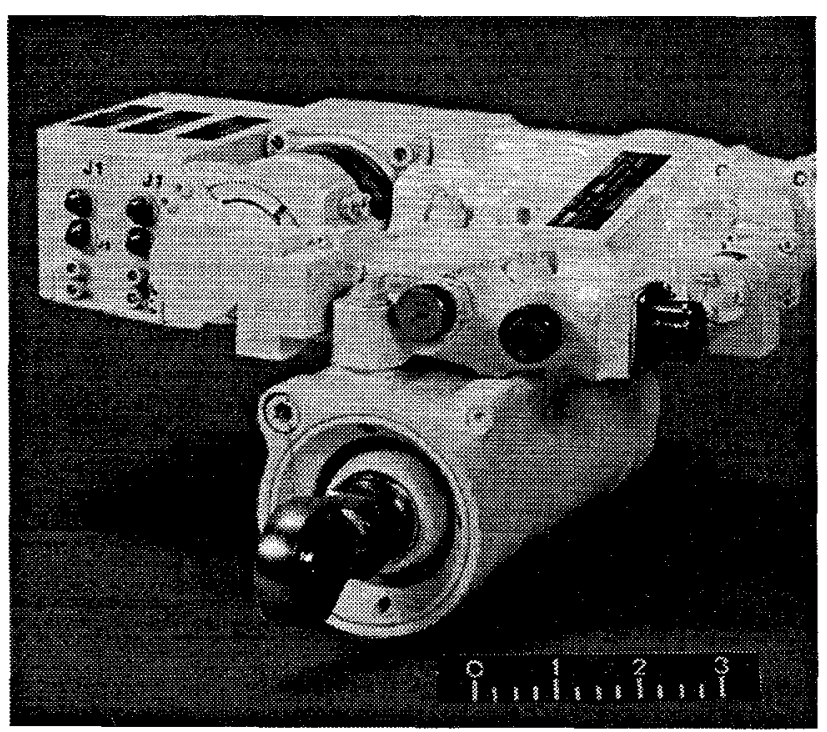

EC93 41023-13

Figure 1. HR Textron smart actuator. 
actuator are fail-operate/fail-safe for electrical failures. The fail-operate mode of the smart actuator results in the continued operation after the detection of a single channel failure. A secondary fault will cause the reversion to the fail-safe mode which is traildamped, identical to the standard F-18 aileron actuator. Reference [1] provides a detailed description of the smart actuator design.

Table 1: General F-18 aileron actuator requirements.

\begin{tabular}{|c|c|}
\hline \multirow{2}{*}{ Output travel } & \pm 2.25 in. (mechanical) \\
\hline & \pm 2.19 in. (electrical) \\
\hline $\begin{array}{l}\text { Output ram velocity } \\
\text { (no load-open loop) }\end{array}$ & $\pm 6.70 \mathrm{in} . / \mathrm{sec}$ \\
\hline \multirow{2}{*}{ Output force } & $\pm 12,093 \mathrm{lb}$ compression (full retract) \\
\hline & $\pm 13,106 \mathrm{lb}$ tension (full extend) \\
\hline \multirow{3}{*}{$\begin{array}{l}\text { Operational } \\
\text { temperature } \\
\text { (ambient air) }\end{array}$} & $-65^{\circ} \mathrm{F}$ to $+160^{\circ} \mathrm{F}$ (continuous) \\
\hline & $220^{\circ} \mathrm{F}(10 \mathrm{~min})$ \\
\hline & $240^{\circ} \mathrm{F}(2.5 \mathrm{~min})$ \\
\hline $\begin{array}{c}\text { Operational } \\
\text { temperature } \\
\text { (hydraulic oil) }\end{array}$ & $-20^{\circ} \mathrm{F}$ to $+275^{\circ} \mathrm{F}$ (operating) \\
\hline Altitude & sea level to $70,000 \mathrm{ft}$ \\
\hline
\end{tabular}

Figure 2 shows the major components of the smart actuator [1]. In addition to the two channel-control electronic modules, a third module is included in the electronic stack for electrical power conditioning. This module is dual redundant with each power channel physically separated internally. Also illustrated is the fiber optic communication interface for each channel of the smart actuator. Each electronic channel has two fiber optic connectors; one for data transmission and one for data reception. The electro-optical components of the fiber optic data link incorporate a subminiature A-type (SMA) connector interface. Because the connector is an integral part of the optical transmitter and receiver, these components are mounted on the front panel of each electronic module enclosure. As a result, the transmitter and receiver are located directly behind the front connector panel of each control channel module and in close proximity to module seams. Although fiber optic cables may be immune to EMI, particular attention should be made in the selection of low-power electrooptic components to minimize potential EMI susceptibility [2].

Electrical power $(28 \mathrm{Vdc})$ is provided to the actuator through a connector located on the top of the manifold (fig. 2). System redundancy is achieved

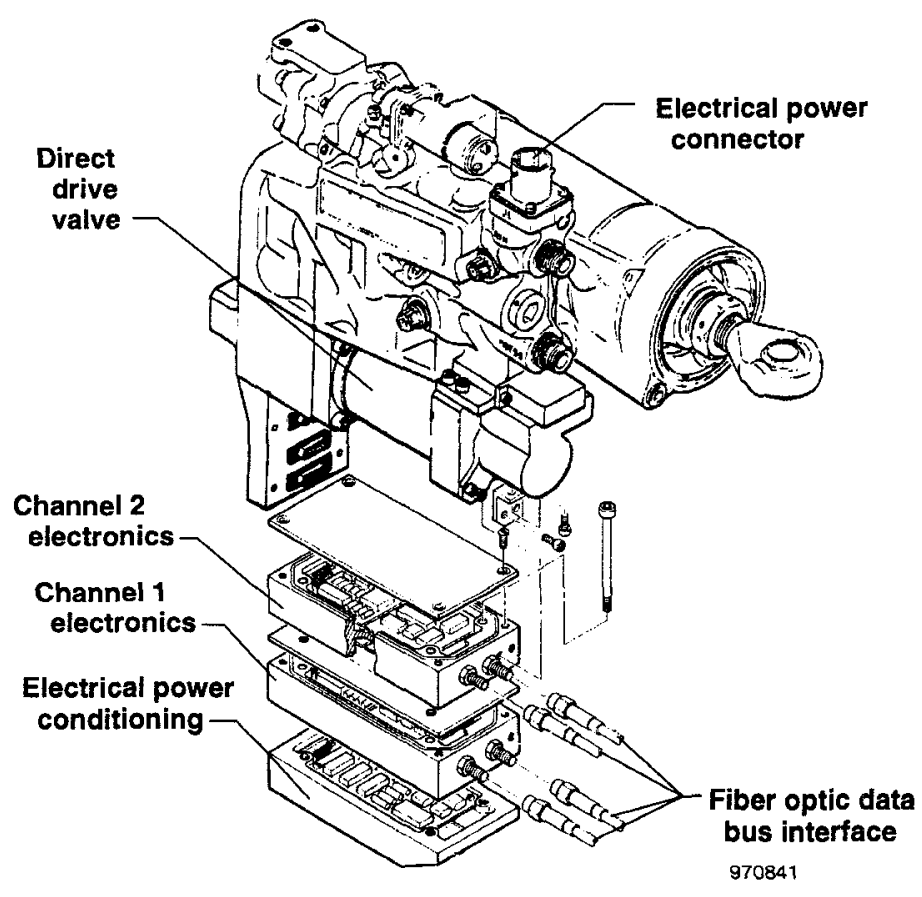

Figure 2. Smart actuator components (reference [1]). 
by electrically isolating the electronic control modules. Each module is supplied with individual $28 \mathrm{Vdc}$ aircraft power lines, and cross-channel communication is provided through optical isolators for electrical separation.

The system architecture for a single channel of the control electronics is shown in figure 3 [1]. Fiber optic communication is accomplished through optical transceivers. The external interface of the electronic modules could have followed the Military Standard Digital Time Division Command/Response Multiplex Data Bus (MIL-STD-1553)[3], as well as any other type of serial interface specification. In this case, an optical transmitter and optical receiver provide the signal conversions for the electrical MILSTD-1553 interface. The fiber optic transmission of the MIL-STD-1553 data is a nonstandard 1773 message transmission protocol developed by HR Textron specifically for this program. For the purpose of further discussions, this nonstandard fiber optic communication will be referred to as 1773 .

The actuator fail-safe condition is the trail-damped mode. This mode is engaged when the control channels release a bypass valve located in the actuator manifold. The bypass valve restricts the rate at which the actuator moves in response to aerodynamic loads on the aileron control surface.
Because the bypass valve is a solenoid-operated valve (SOV), electronic release of the bypass valve is accomplished by turning off the SOV electrical power. The bypass valve is opened by a return spring in the manifold. As an added safety measure for flight test purposes, the SOV circuit includes an override switch located in the aircraft cockpit for manually disabling the actuator.

\section{AIRCRAFT INTEGRATION}

The smart actuator was installed on the NASA F-18 Systems Research Aircraft (SRA); tail number 845 (fig. 4). This aircraft has been used extensively as a test bed facility for aircraft systems research. The smart actuator was installed in the left aileron actuator bay (fig. 5). To accommodate the electronic modules, production $3 / 8$ in. diameter hydraulic lines were replaced with $1 / 4$ in. diameter lines and rerouted over the top of the actuator. This modification slightly degraded the performance of the actuator and will be discussed later.

To accommodate rapid system integration and flight test requirements of the SRA, modifications to the production F-18 FCC's were prohibited. As a result, an interface box developed by Dynamic Controls, Incorporated (DCI), Dayton, Ohio, provided the

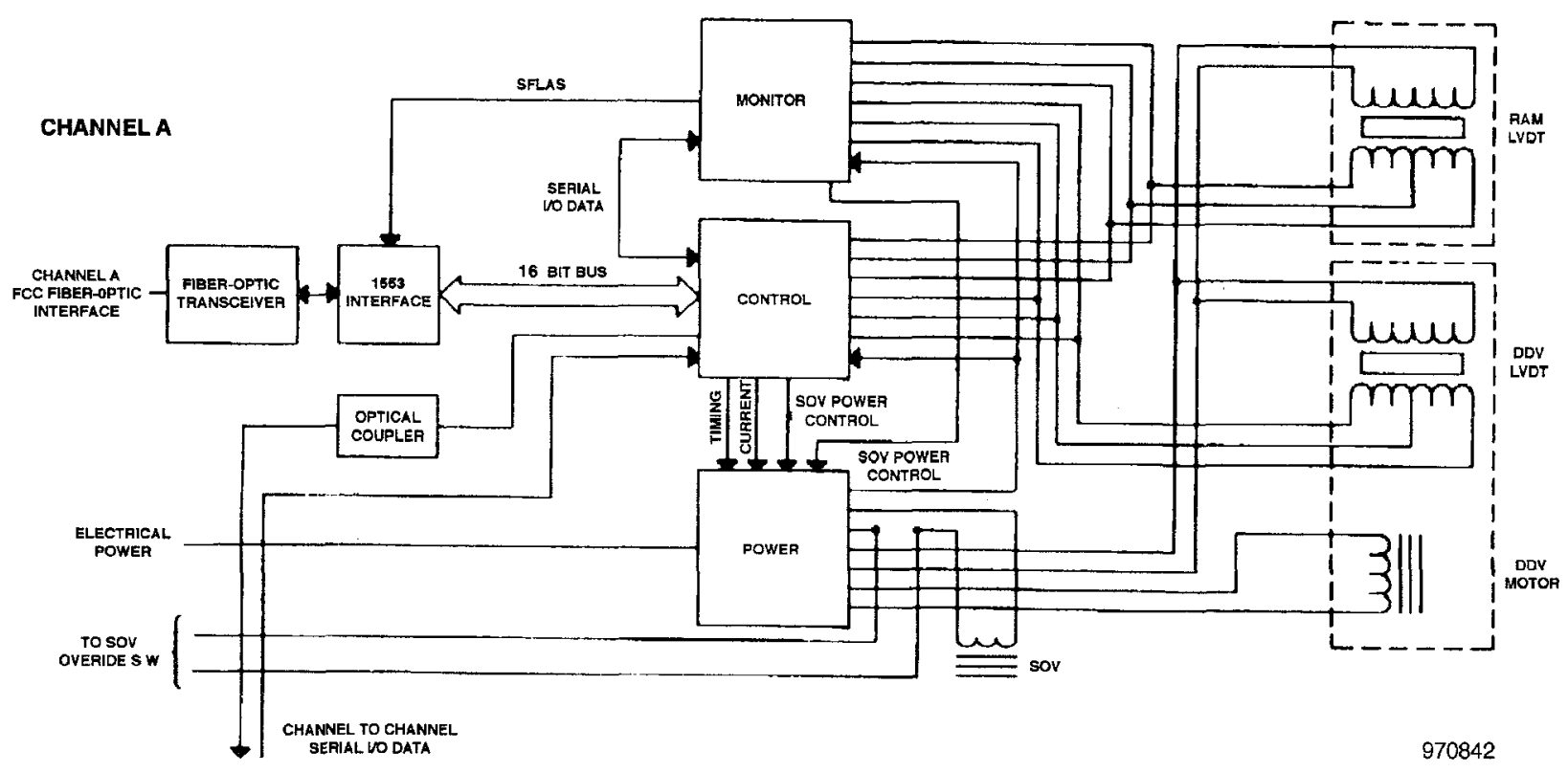

Figure 3. Smart actuator control channel architecture (reference [1]). 


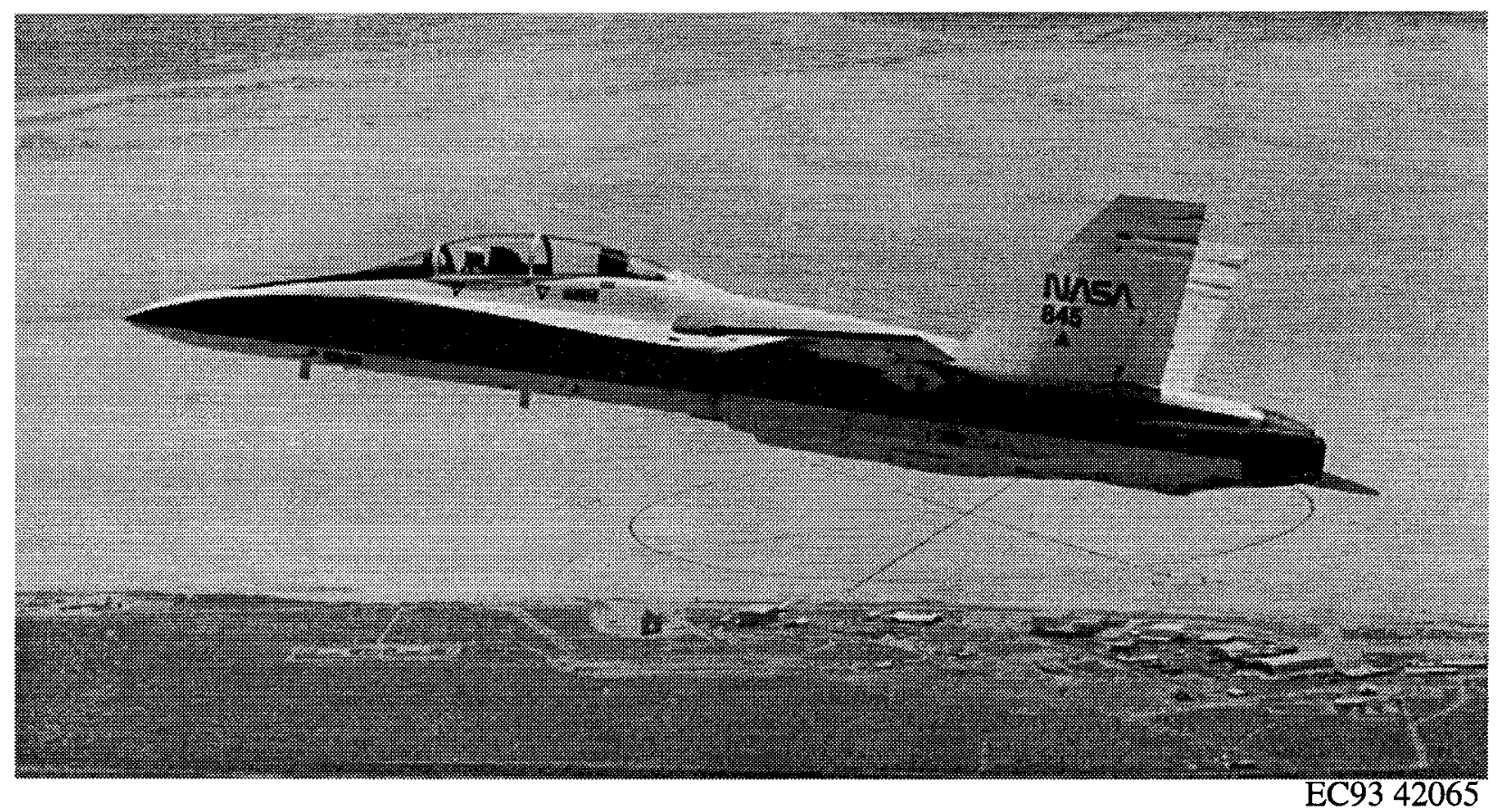

Figure 4. NASA F-18 Systems Research Aircraft.

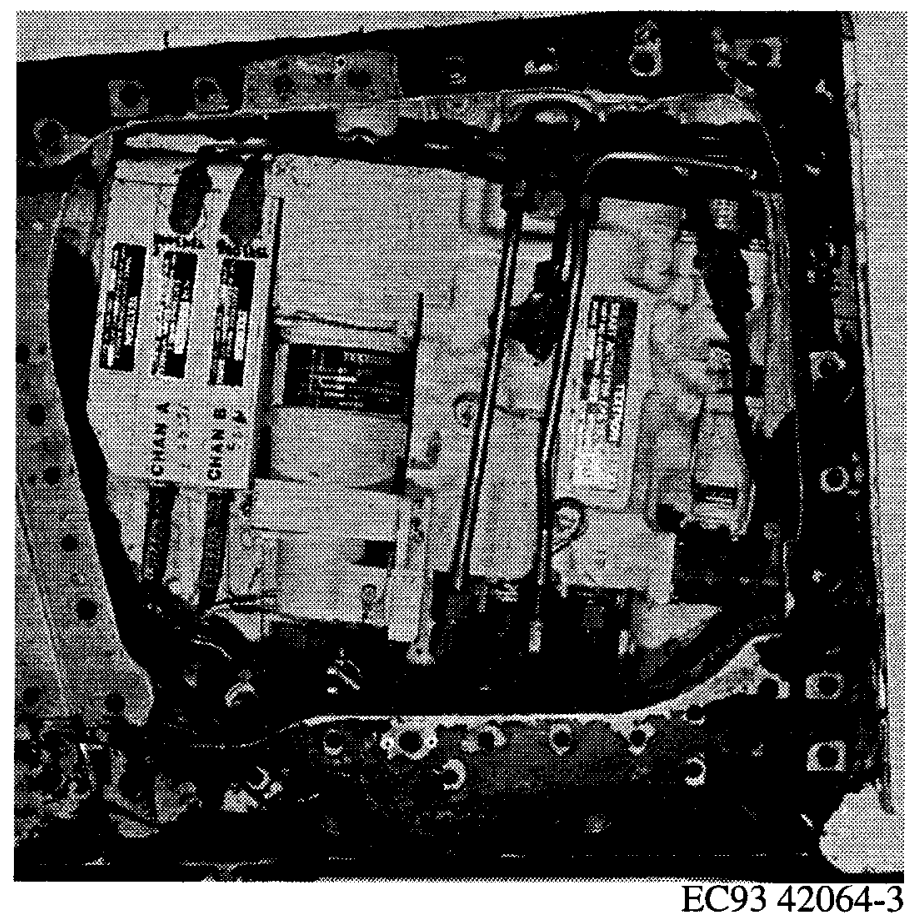

Figure 5. Smart actuator installation. 
electrical interface for the flight control computers and the fiber optic interface for the smart actuator. To meet F-18 redundancy requirements, two interface boxes were used for aircraft integration. The interface box provided real-time system data to the aircraft instrumentation system. Figure 6 shows the smart actuator system configuration on the F-18 SRA.

The interface box provides a means to control the operational modes of the smart actuator. The required cockpit modifications for this function were the installations of a pilot override switch and a system control panel. The override switch provides the pilot with a direct method of forcing the smart actuator and the interface boxes to the fail-safe mode. Actuator power, interface box mode settings, initiated built-in tests (IBIT), and system resets were controlled through the use of the system control panel.

\section{INTERFACE BOX DESIGN DESCRIPTION}

Figure 7 shows the interface box. This box was designed to meet the following basic system requirements:

- Provide the smart actuator fiber optic interface.

- Provide the FCC electrical interface.

- Provide pilot interface for system control and override capability.

- Provide real-time system data to the aircraft instrumentation system.

This interface box provides a fiber optic interface by using the identical optical transmitter and receiver as those used in the smart actuator. The connector portion of these components can be identified on the front

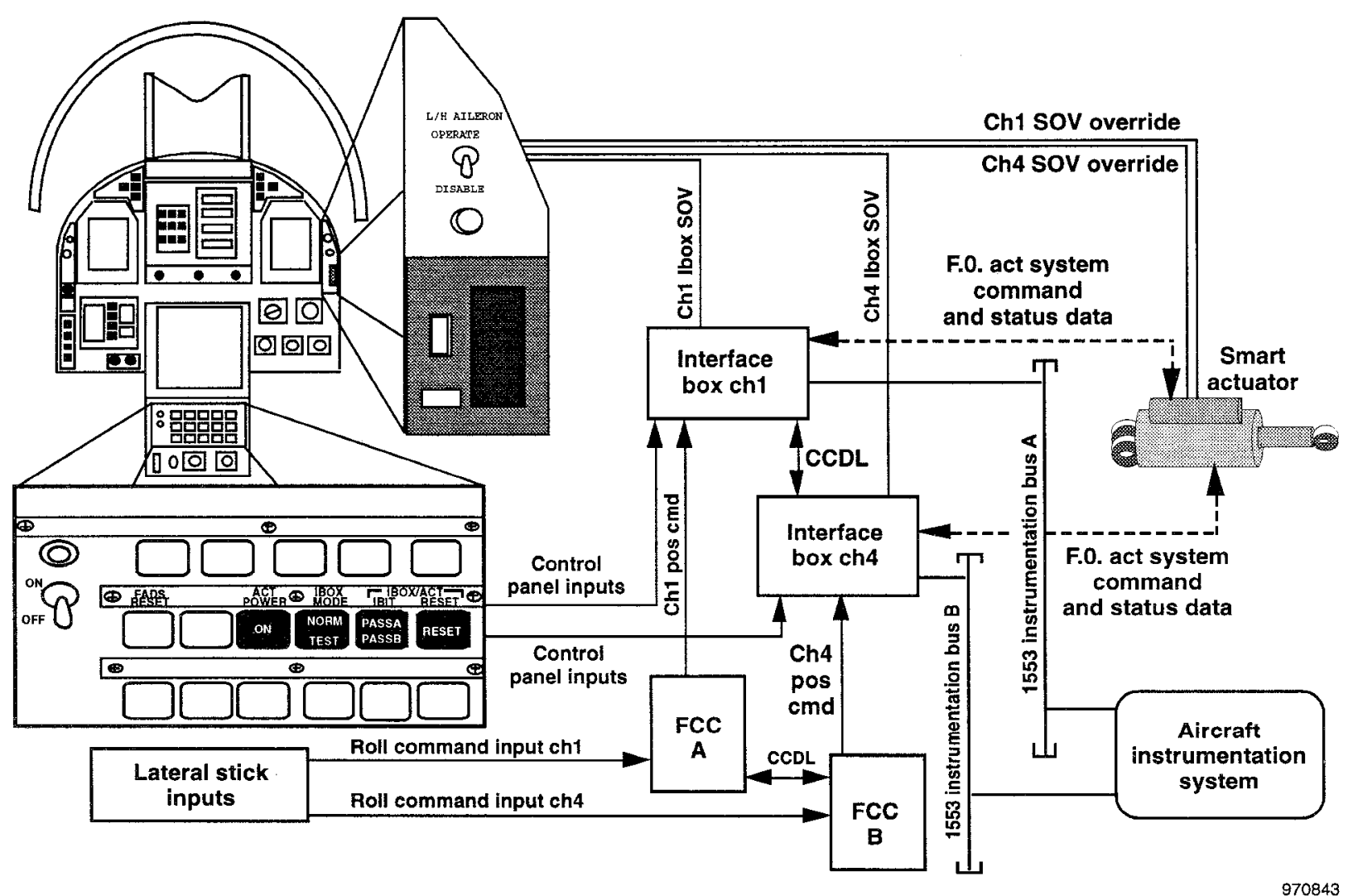

Figure 6. Aircraft system architecture. 
panel of the enclosure by the labels " $T$ " for transmitter and " $R$ " for receiver. For the purposes of bus communication, the interface box is designed to act as the 1773 bus controller, while the smart actuator is designed as a remote terminal (RT).

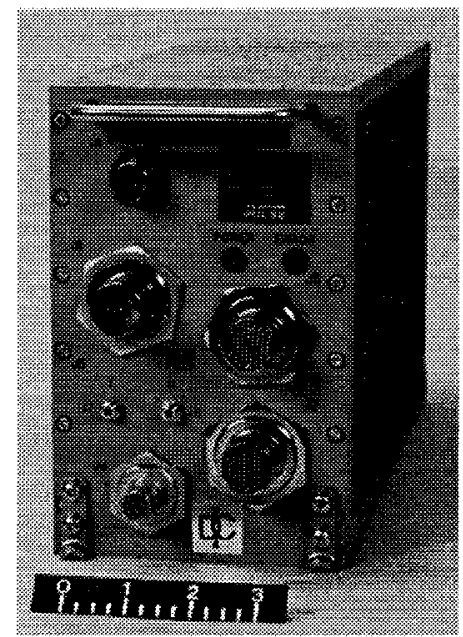

EC93 41023-9

Figure 7. DCI interface box.

Figure 8 shows the functional block diagram of the FCC to interface-box integration. The functional block is comprised of three sections: FCC software, FCC hardware, and interface box hardware. Since the smart actuator performs local closed-loop control functions, absolute position commands need to be provided to the smart actuator by the interface box. Delta position commands to the actuator exit the FCC servoamplifier hardware and enter the interface box hardware. The interface box analog hardware contains a high response actuator model that converts the delta command to an absolute actuator position. The actuator model output signal is used as the position command for the smart actuator. In this way, the interface box is able to generate a test actuator position command for transmission to the smart actuator with minimal latency.

The actuator model output is used as a position feedback signal to the FCC actuator control loop. The FCC is not provided with the actual position of the smart actuator, and therefore cannot detect actuator failures. The electronic modules of the smart actuator perform all servoredundancy and servocontrol-loop functions. However, as in the actuator design, the interface box includes an SOV-like discrete signal as a manual override command for flight test purposes. If the smart actuator detects a failure internally or upon selecting the override switch, the interface box will automatically open the position feedback signal to the FCC (fig. 8). This action triggers the control loop failure-monitoring functions of the FCC and opens the actuator bypass valve, forcing the system to the fail-safe condition.

The interface box design also provides system commands to the actuator. Through the use of a

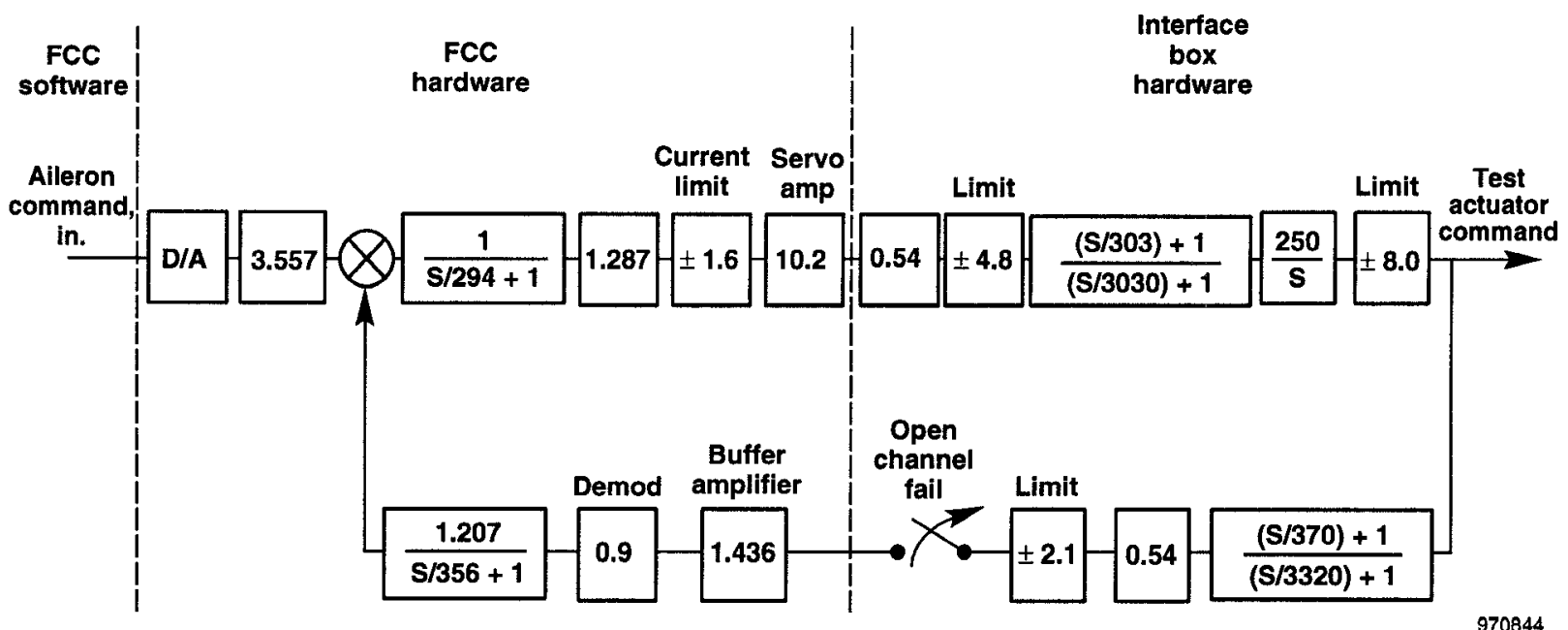

Figure 8. Ibox actuator model functional diagram. 
cockpit control panel, the interface box can command system modes, including IBIT. The interface box accesses system health information from the smart actuator through the 1773 data interface and echoes the data stream on a dedicated 1553 bus to the aircraft instrumentation system for recording.

\section{GROUND TESTING}

Flight qualification tests of the smart actuator performed by the manufacturer were limited to vibration testing, NASA DFRC performed altitude and temperature tests. Upon successful completion of vibration tests, the flight unit was delivered to NASA DFRC for system integration testing in the NASA Research Aircraft Integration Facility (RAIF).

\section{System Integration Tests}

System integration tests were performed with the F-18 hardware-in-the-loop (HIL) test bench. The F-18 test bench contains two FCC's and the capability to integrate analog models of surface actuators or real flight hardware. In addition, the test bench can be integrated with the Iron Bird (which is a retired F-18 airframe) as well as with the F-18 real-time simulation. For the purpose of conducting comprehensive integration tests, the smart actuator system hardware (including the interface boxes) was installed on the F-18 Iron Bird and integrated with the test bench. Test bench and Iron Bird modifications for integration included system control switches, representative hydraulic lines, and failure insertion capability.

System integration tests included functional tests, performance tests, verification and validation tests, and failure modes and effects tests. The performance of the actuator proved to be acceptable with test requirements throughout all of the system integration tests. As shown in figure 9, the no-load frequency response of the smart actuator system compared well with that of the production actuator on the right aileron. The hydraulic line size reduction, however, reduced the normal no-load slew rate of the smart actuator by 10 percent. The reduced slew capability from $7.6 \mathrm{in} / \mathrm{sec}$ to $6.8 \mathrm{in} / \mathrm{sec}$ resulted in an intermittent IBIT failure for position rate tests. Although the lower slew rate met design specifications, the smart actuator self-test software limit was reduced to $6.7 \mathrm{in} / \mathrm{sec}$, which remedied the IBIT anomaly.

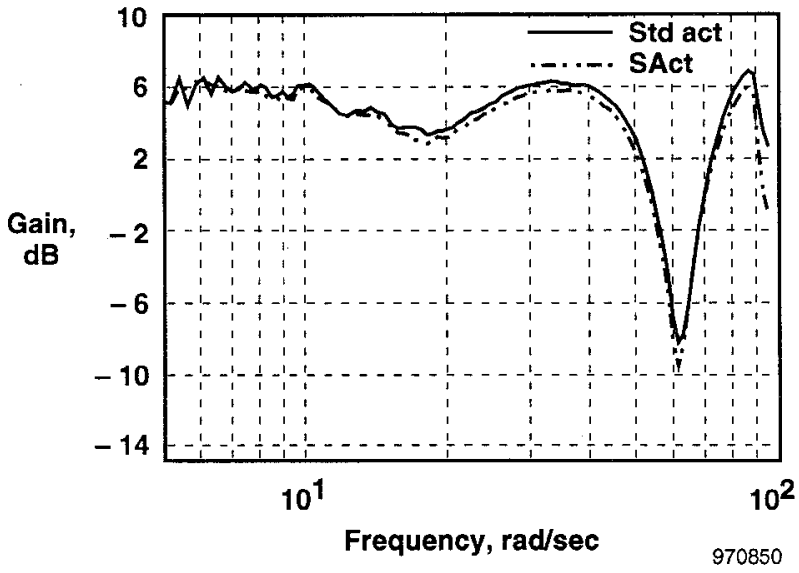

(a) Gain, dB.

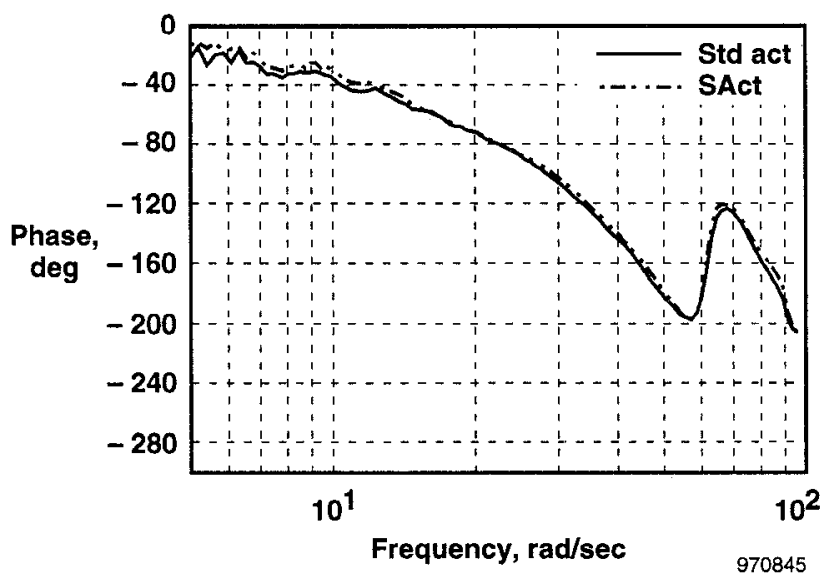

(b) Phase, deg.

Figure 9. Smart actuator frequency response comparison with standard actuator.

The use of fiber optics simplified the system integration on the Iron Bird. However, this new technology complicated the approach for verifying and validating system operation. During initial system integration efforts, it became apparent that the optical data stream could not be objectively verified without some intrusive means. Any attempts to tap the 1773 data link affected the optical power and resulted in communication faults. Because the system was designed for point to point communication links, the optical power loss eliminated the possibility of adding an RT to the bus as with MIL-STD-1553 architectures for monitoring. To overcome this obstacle, 1773 data communication was confirmed by using special test 
software loads in the interface boxes to create a MIL-STD-1553 data stream. In this respect, the interface box had become an invaluable tool for system tests involving the fiber optic data link.

A significant observation was made during actuator integration with the DCI interface box. High optical power levels input to the receiver were shown to create up to a 40 percent duty cycle distortion in the detected 1773 waveform. The result was the possibility of receiver saturation, so an effort to define a nominal optical power range was undertaken. DCI conducted sample tests of fiber optic transmitter and receiver components with the same part number. The results showed a wide variation in transmitter output and receiver sensitivity. The lack of consistency of industry fiber optic components made it very difficult to establish a general setup criteria for the 1773 data links, and is unacceptable for aerospace applications. A similar lack of consistency in industry fiber optic connectors is discussed in reference [4]. The receiver circuit also displayed a dc shift in the detected waveform, which was significantly reduced with minimum optical power levels.

\section{Environmental Testing}

Because the smart actuator had completed vibration tests, vibration tests conducted at NASA DFRC were only performed for the interface boxes. These tests were completed without any significant difficulties. Temperature and altitude tests were performed on the interface boxes and the smart actuator. These tests were performed with the smart actuation system operational.

Temperature and altitude testing of the actuator system revealed additional sensitivities with respect to the optical components of the 1773 data link. Initial environmental tests were intended to validate the system operation through the required altitude range $(2300 \mathrm{ft}$ to $50,000 \mathrm{ft})$ and the required temperature range $\left(-65{ }^{\circ} \mathrm{F}\right.$ to $\left.220{ }^{\circ} \mathrm{F}\right)$. The smart actuator and the interface boxes were placed in separated chambers because the actuator was to be installed in an environmentally uncontrolled location in the aircraft, while the interface boxes were to be located in an environmentally controlled avionics bay.
Although no anomalies were observed throughout the altitude tests, the actuation system consistently failed as the interface box temperatures and smart actuator temperature reached a difference of $100{ }^{\circ} \mathrm{F}$. Bench testing of limited optical component samples by DCI documented performance variations over the temperature range of $77{ }^{\circ} \mathrm{F}$ to $175{ }^{\circ} \mathrm{F}$. Optical receivers exhibited increased sensitivity of up to 50 percent with increased temperature. Similarly, optical transmitter power output decreased 20 percent with increased temperature.

Additional DFRC environmental temperature tests confirmed DCI test data. Receiver saturation was an immediate concern and previous test data indicated that minimum optical power to the receiver reduced 1773 waveform distortion. Based on this information, a fiber optic sensitivity analysis was conducted in the NASA DFRC environmental lab. Allowing the smart actuator to reach a nominal operating temperature of $150^{\circ} \mathrm{F}$, both interface boxes 1 and 2 were thermally cycled from $-10{ }^{\circ} \mathrm{F}$ to $170{ }^{\circ} \mathrm{F}$. At specified temperature intervals, the minimum optical power level for each 1773 communication link was determined. As shown in table 2, interface box 1 and 2 failure power levels decreased 21.7 percent and 18.6 percent, respectively, with increased temperature. This corresponds to $2.13 \mathrm{~dB}$ and $1.78 \mathrm{~dB}$ variation in optical power over the temperature range.

Table 2: Fiber optic thermal sensitivity data.

\begin{tabular}{c|c|c}
\hline \hline & $\begin{array}{c}\text { Interface box 1 } \\
\text { transmitter }\end{array}$ & $\begin{array}{c}\text { Interface box 2 } \\
\text { transmitter }\end{array}$ \\
\hline $\begin{array}{c}\text { Temperature, } \\
{ }^{\circ} \mathrm{F}\end{array}$ & $\begin{array}{c}\text { Failure optical } \\
\text { power level, } \mu \mathrm{W}\end{array}$ & $\begin{array}{c}\text { Failure optical } \\
\text { power level, } \mu \mathrm{W}\end{array}$ \\
\hline-10 & 17.25 & 19.52 \\
10 & 17.13 & 19.42 \\
30 & 16.87 & 19.20 \\
50 & 16.48 & 18.75 \\
70 & 15.94 & 18.31 \\
90 & 15.25 & 17.70 \\
110 & 14.98 & 17.34 \\
130 & 14.59 & 17.08 \\
150 & 14.02 & 16.51 \\
170 & 13.50 & 15.89 \\
\hline \hline
\end{tabular}


Given the temperature profiles that the interface boxes and the smart actuator were to be exposed to in flight, the data in table 2 does not represent a worst-case condition for the system. As a result, an additional thermal study was performed to determine the minimum optical power requirement for system calibration. The environmental conditions were defined such that each 1773 data link would be exposed to a high transmitter temperature $\left(160^{\circ} \mathrm{F}\right)$ and a low receiver temperature $\left(0{ }^{\circ} \mathrm{F}\right)$. This condition resulted in low receiver sensitivity and low transmitter output: a low light condition. The minimum optical power was determined by measuring the power level at which the system communications faulted and adding a 3-dB safety factor to account for dynamic variation with temperature. By calibrating the system to the minimum optical power level, receiver saturation and waveform distortion were minimized. Because of the wide variations in the performance of individual electro-optic components, each receiver required a unique power level, as shown in table 3.
Table 3: Fiber optic system receiver power requirements.

\begin{tabular}{c|c|c}
\hline \hline \multicolumn{2}{c|}{ F.O. components } & $\begin{array}{c}\text { Required F.O. } \\
\text { power level, } \mu \mathrm{W}\end{array}$ \\
\hline Transmitter & Receiver & \\
\hline Smart act ch 1 & Ibox 1 & $2.7 \pm 1.0$ \\
Smart act ch 1 & Ibox 2 & $5.47 \pm 1.0$ \\
Smart act ch 2 & Ibox 3 & $4.76 \pm 1.0$ \\
Smart act ch 2 & Ibox 4 & $2.18 \pm 1.0$ \\
Ibox 1 or 2 & Smart act ch 1 & $15.92 \pm 1.0$ \\
Ibox 3 or 4 & Smart act ch 2 & $19.95 \pm 1.0$ \\
\hline
\end{tabular}

In all cases, optical attenuation was necessary to achieve the required power levels. Fiber optic attenuation was achieved by introducing an air gap between the fiber optic connector and the optical transmitter. The air gap was adjusted by inserting shim spacers over the end of the SMA connector on the transmission side of each data link. Shim spacers were available in assorted thickness from 2-20 mils. Figure 10 shows the fiber optic connector, while

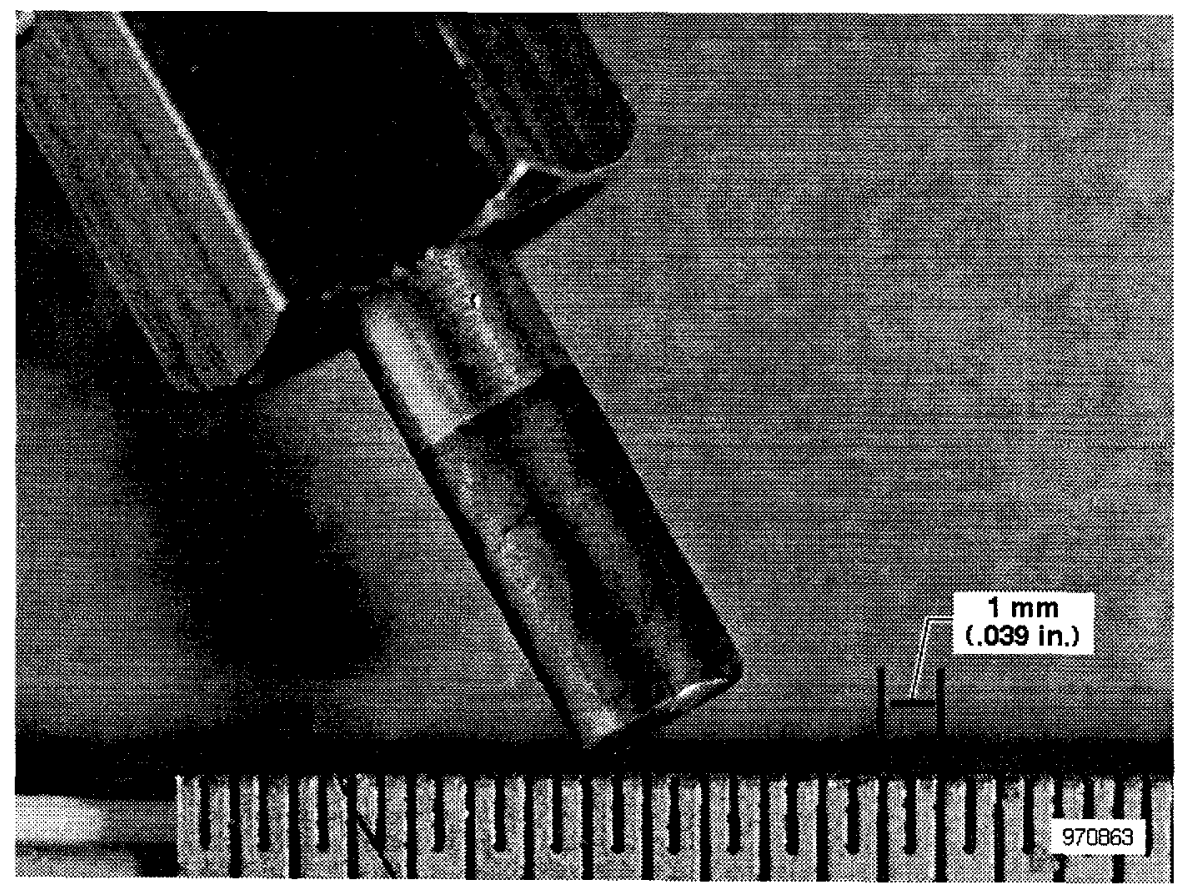

Figure 10. SMA fiber optic connector. 
figure 11 illustrates how shim spacers of varying thickness were used. Although this was a very simple solution to a complex problem, subsequent environmental tests were completed without any failures. The calibration procedure was documented and utilized throughout the flight test program for checking fiber optic light levels.

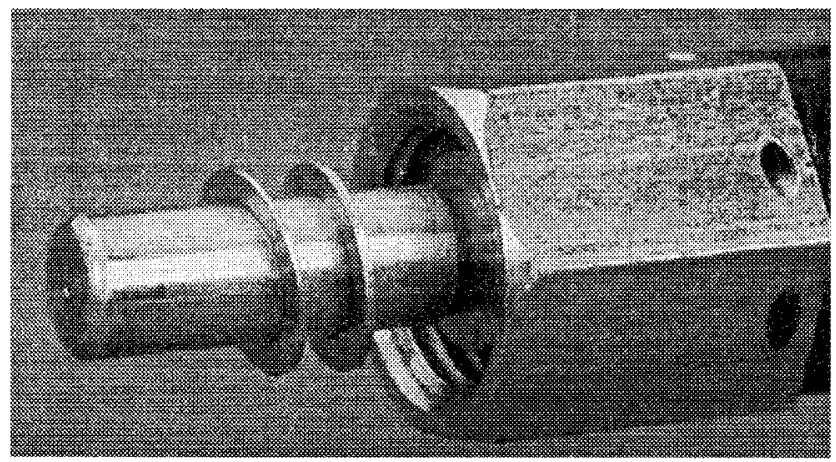

ED97-43948-1

Figure 11. SMA connector with calibration spacers.

As an additional environmental study, terminated and unterminated fiber optic cables were subjected to 8 thermal cycles between $-40{ }^{\circ} \mathrm{F}$ and $220^{\circ} \mathrm{F}$. It was observed that the cabling hardware could also contribute to variations in the optical power level. Figure 12 illustrates the shrinkage $(0.87 \mathrm{in}$.) of the outer jacket that was induced by thermal cycling. As shown in figure 13, a piston-like effect was also observed in the terminated cable. The SMA crimp and cleave termination did not utilize any epoxy or mechanical design to fix the fiber, which resulted in fiber exposure. Because the termination was crimped onto the outer jacket of the cable, the amount of exposed fiber was a function of outer jacket shrinkage. Thermal testing indicated that the fiber could be exposed as much as 50 mils. It is important to note that since the completion of this program, preconditioned fiber optic cable is now available and improvements in fiber optic termini have been made. Nonetheless, these factors must be considered when generating fiber optic system specifications. Additional issues regarding fiber optic cable assemblies are discussed in reference [5], and specifications regarding the termination and installation of fiber optics are documented in NASA Standard $8739.5[6]$.

\section{Aircraft Installation}

Upon completing system integration tests and documenting the valuable fiber optic lessons in the form of aircraft procedures, the smart actuation system was installed on the F-18 SRA. There were no anomalies throughout the installation, calibration, and functional checks of the smart actuator. The use of fiber optics significantly simplified the entire installation process. This was primarily because of a significant reduction in wire count as opposed to the production actuator interface. Table 4 contains data that supports this benefit of fiber optic technology. An aggregate reduction of the cable harness components was just over a factor of 3 (69.2 percent reduction), which directly relates to a total weight savings of 62.3 percent. In addition, the installation time was reduced by a factor of 2 when compared to the production actuator wiring installation.

Table 4: Smart actuator wire reduction data.

\begin{tabular}{c|c|c|c|c}
\hline \hline & $\begin{array}{c}\text { Total number } \\
\text { of electrical } \\
\text { conductors, } \\
47 \mathrm{ft}\end{array}$ & $\begin{array}{c}\text { Total } \\
\text { number } \\
\text { of fibers, } \\
47 \mathrm{ft}\end{array}$ & $\begin{array}{c}\text { Total } \\
\text { harness } \\
\text { items }\end{array}$ & $\begin{array}{c}\text { Total weight } \\
\text { (including } \\
\text { termination } \\
\text { hardware) }\end{array}$ \\
\hline $\begin{array}{c}\text { Standard } \\
\text { aileron } \\
\text { actuator }\end{array}$ & 26 & 0 & 26 & $\begin{array}{c}10.37 \mathrm{lb} \\
(4705.5 \mathrm{gm}) \\
3.91 \mathrm{lb}\end{array}$ \\
$\begin{array}{c}\text { Smart } \\
\text { actuator }\end{array}$ & 4 & 4 & 8 & $\begin{array}{c}(1774.5 \mathrm{gm}) \\
\begin{array}{c}\text { Percent } \\
\text { change }\end{array}\end{array}$ \\
\hline \hline
\end{tabular}

\section{FLIGHT TEST}

The smart actuator program completed 31.5 hours of flight test time over a period of 9 months. The objectives of the flight test program were as follows:

- Demonstrate the operation of the smart actuator throughout the F-18 flight envelope using increasing actuator load as the primary test parameter.

- Evaluate the smart actuator performance using the production actuator as the baseline.

- Evaluate the performance of fiber optic data links. 


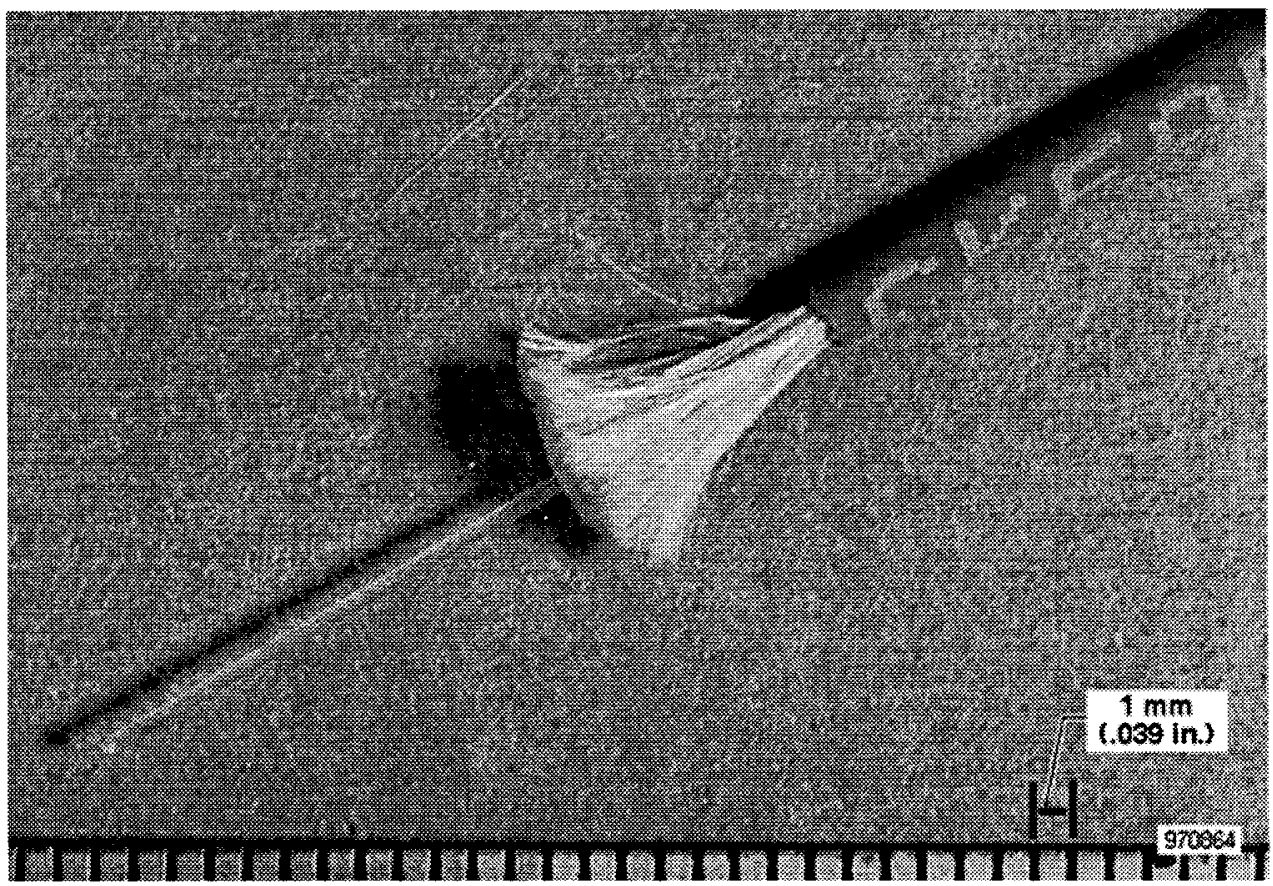

Figure 12. Fiber optic cable shrinkage.

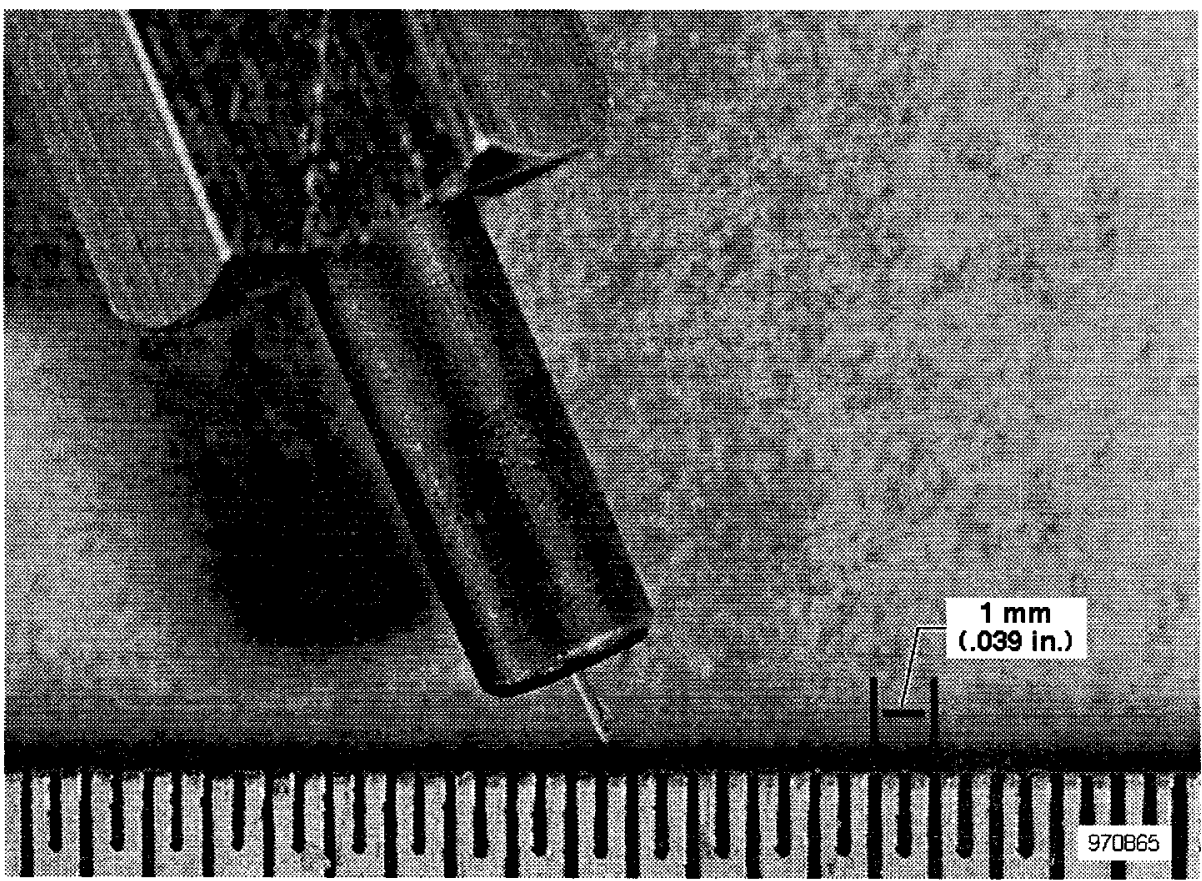

Figure 13. Fiber exposure of SMA connector. 
The smart actuator was evaluated during the following flight test maneuvers:

- Lateral stick doublets and frequency sweeps

- Aileron reversals

- Level turns (maximum $g$ or $\alpha=20^{\circ}$ )

- $1 g$ high alpha

- $4 g$ loaded rolls

- Mission profiles

\section{Actuator Performance}

Performance evaluation of the smart actuator, using the production right actuator as a baseline, was initially conducted by performing maneuvers both to the right and the left. However, without computergenerated test inputs, the maneuvers were not consistent enough to allow for direct comparison. Because the F-18 control system provides equal and opposite sign commands to the ailerons, acceptable comparisons were made with inverted right aileron position data. Although the aerodynamic loads were not identical, this method was suitable for comparison.

The performance and reliability of the smart actuator throughout the flight test program was exceptional. There were no in-flight anomalies, and the smart actuator was virtually identical in performance to the production F-18 aileron actuator. Flight test data presented in figures 14 and 15 show the performance of the smart actuator during the execution of an aileron reversal at two different dynamic pressure (q) flight conditions.

Figure 14 represents the aileron reversal performed at a low-q flight condition $\left(88 \mathrm{lb} / \mathrm{ft}^{2}\right)$. In figure $14(\mathrm{a})$ and $14(b)$, the smart actuator closely tracks each corresponding channel position command. Figure 14(c) illustrates the performance of the smart actuator, which controls the left aileron, compared to that of the standard right aileron actuator. Again, the flight data show that the smart actuator performance correlated very well with the production actuator.

The flight data presented in figure 15 represents an aileron reversal performed at a high-q flight condition $\left(884 \mathrm{lb} / \mathrm{ft}^{2}\right)$. In this case, the actuator loading is significantly higher. As expected, the actuator clearly illustrates significant stall character-istics. Figures 15(a) and 15(b) show that the actuator can not achieve the commanded position in the area where it is used to reverse aircraft rolling. In this high aerodynamic load condition, the smart actuator differs from the position command as much as 0.7 in.

However, when compared to the performance of the standard right aileron actuator (fig. 15(c)), the difference is less significant. This indicates that the right aileron actuator is also at a stall condition. The difference in maximum position between the smart

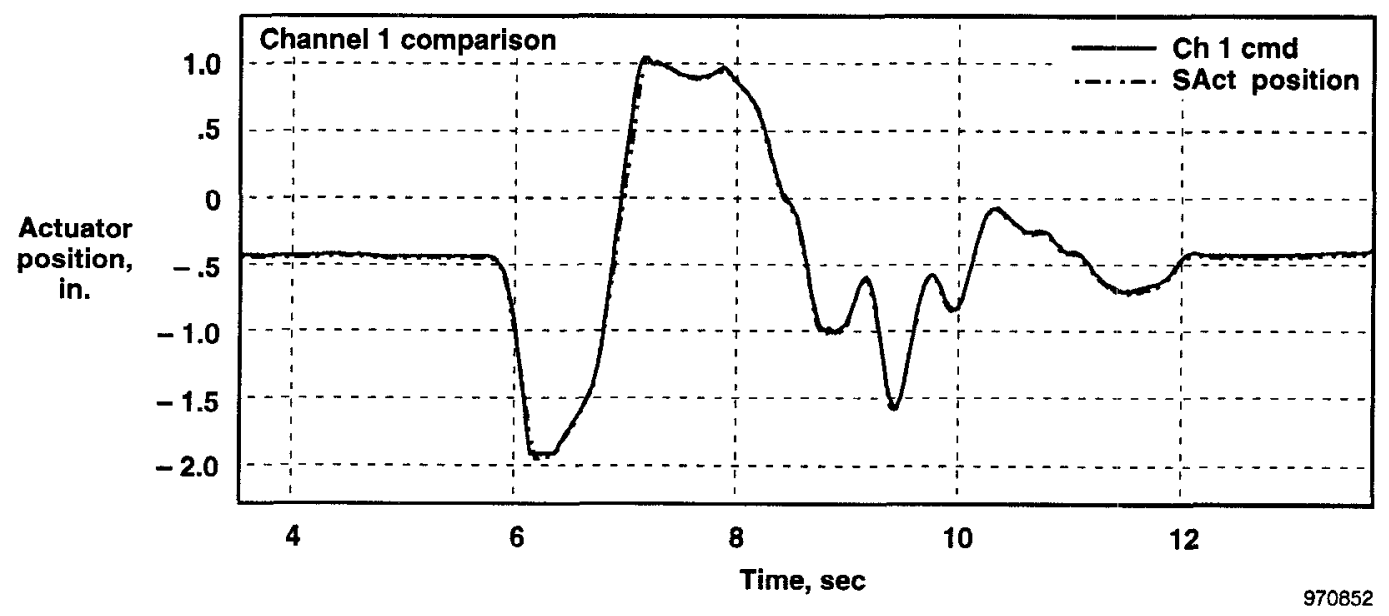

(a) Ch 1 command.

Figure 14. Aileron reversal $\pm 60^{\circ}$ bank angle, $24 \mathrm{kft}, 0.4 \mathrm{M}, 88 \mathrm{q}$. 


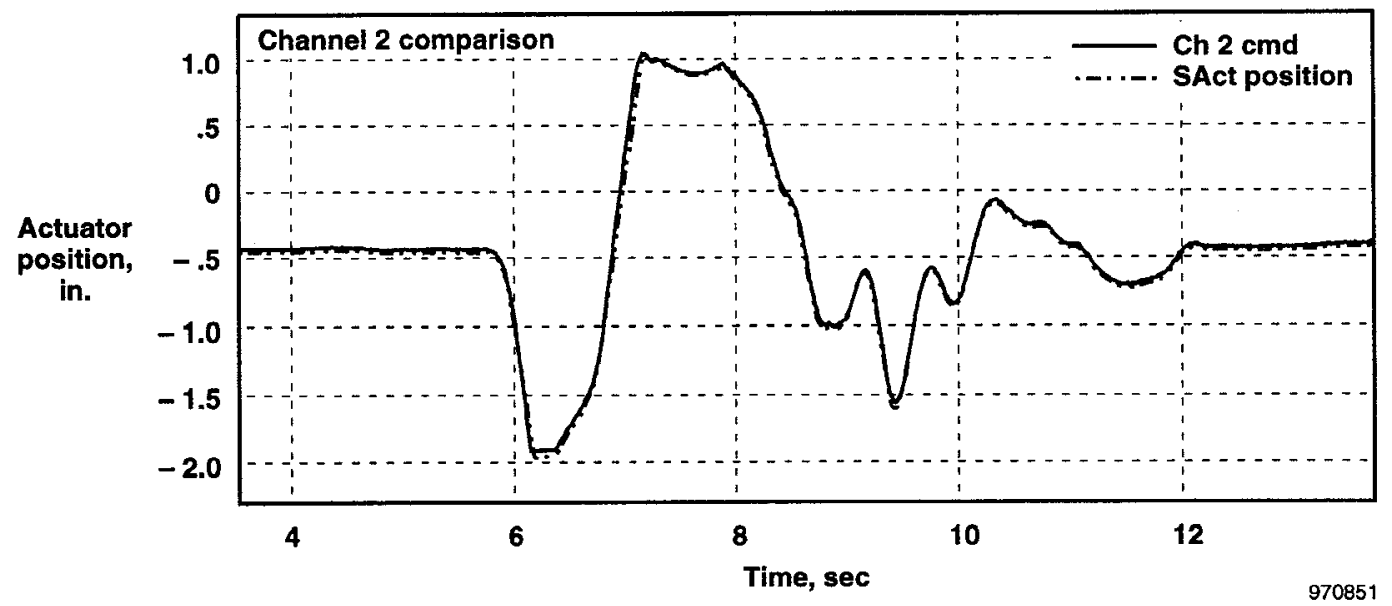

(b) Ch 2 command.

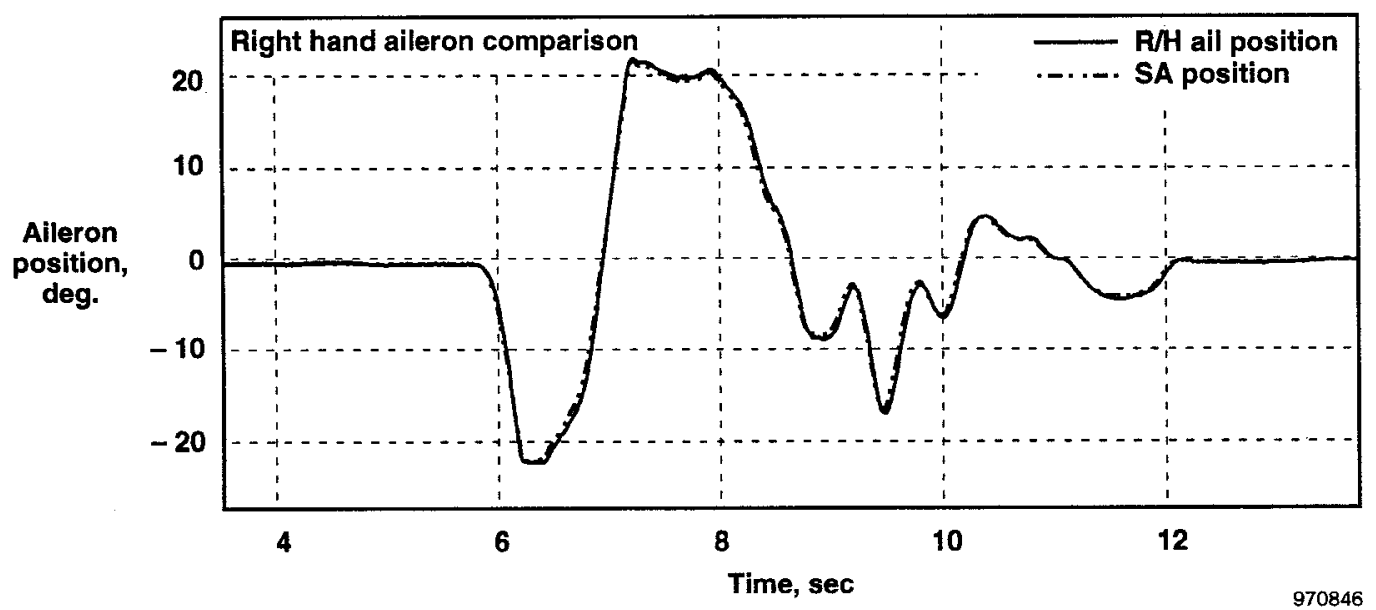

(c) $\mathrm{R} / \mathrm{H}$ ail position.

Figure 14. Concluded.

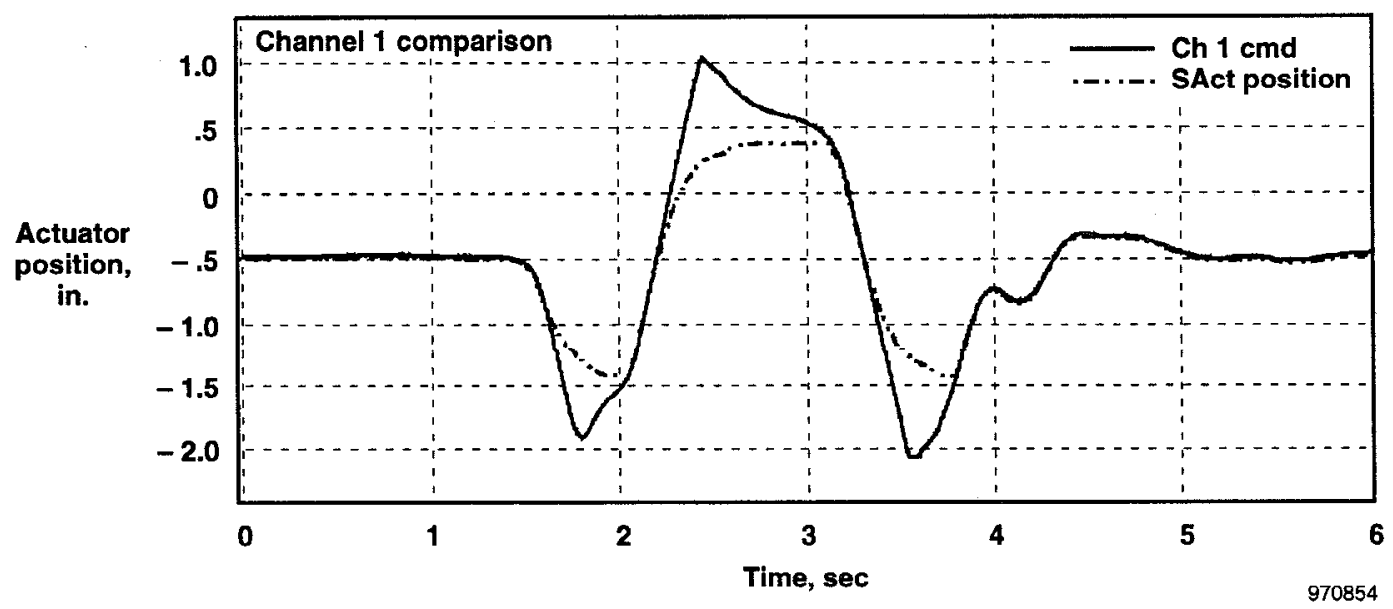

(a) Ch 1 command.

Figure 15. Aileron reversal $\pm 60^{\circ}$ bank angle, $35 \mathrm{kft}, 1.6 \mathrm{M}, 884 \mathrm{q}$. 


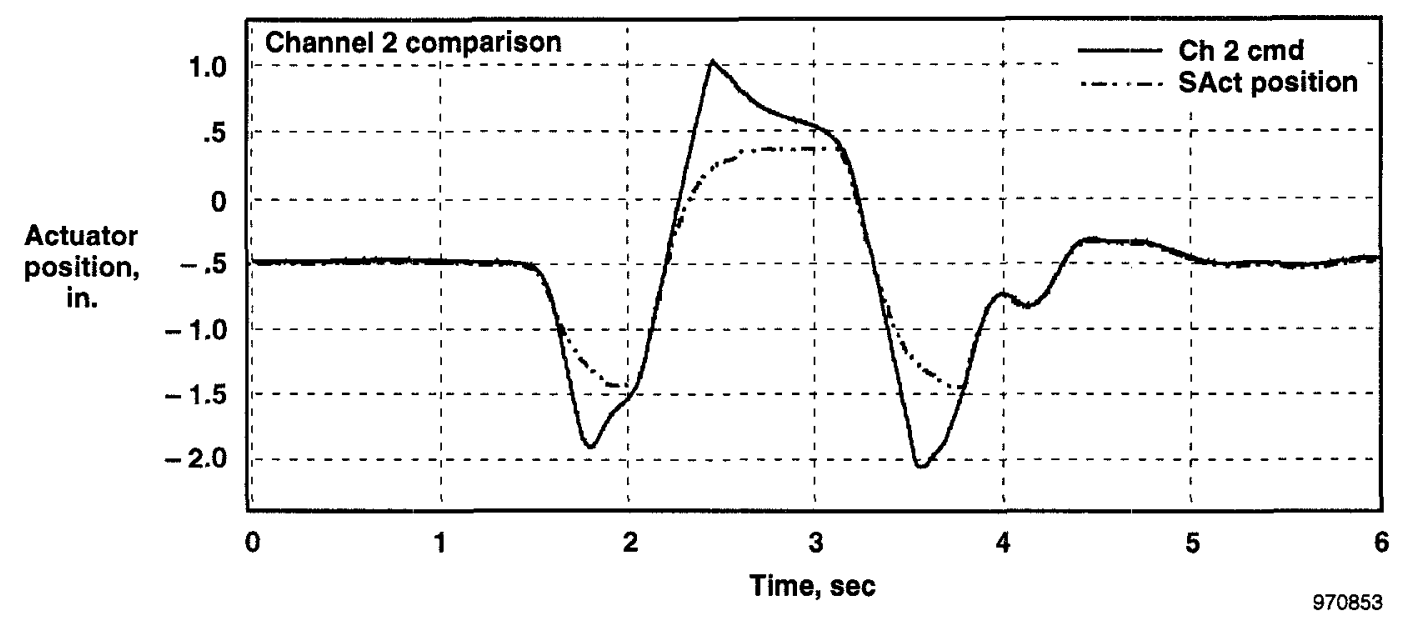

(b) Ch 2 command.

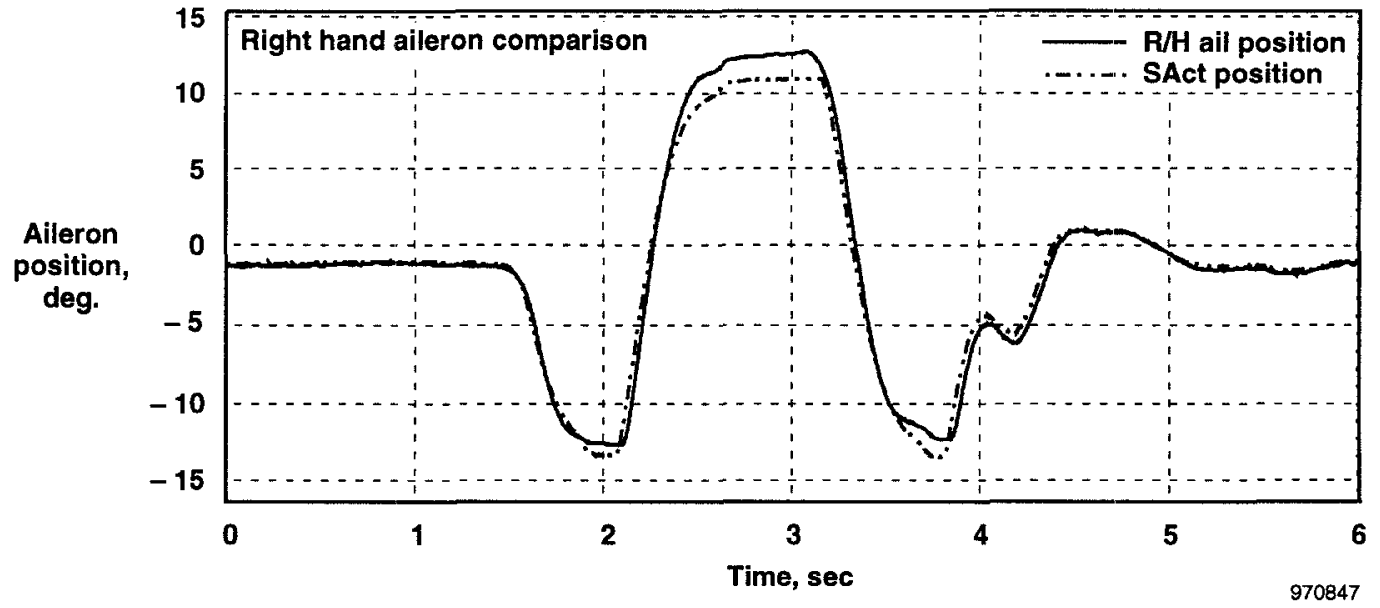

(c) $\mathrm{R} / \mathrm{H}$ ail position.

Figure 15. Concluded.

actuator and the inverted right aileron actuator is due to unsymmetric aerodynamic loads. The position of the aileron surface at which the aerodynamic forces result in a zero-hinge moment is approximately $-4^{\circ}$ (trailing-edge up). Since aircraft roll is commanded with differential aileron, a differential $10^{\circ}$ aileron position, for example, will not result in symmetric actuator loads.

In terms of aircraft control, the smart actuator performance proved that local or smart control of surface actuators is possible. It should be emphasized that this area of evaluation must be separated from the fiber optic data that this program provided.

\section{Fiber Optic Maintenance Data}

As discussed in the Smart Actuator Design Description section of this paper, the front end interface of the smart actuator could have been any type of serial interface. The system calibration issues that were discovered were related to the selection of an optical interface. In this respect, the fiber optic experience gained through the smart actuator program was invaluable. Fiber optic calibration data was recorded throughout the flight test program of the smart actuator. Although there were no in-flight anomalies due to 1773 communication faults, valuable 
results were obtained through periodic recalibration of the optical power levels. Figure 16 contains the required optical calibration data for each 1773 transmitter. Again, note that each communication link requires a unique transmitter power level, as defined by initial environmental tests. Through the adjustment of shim spacers, sufficient calibration levels of all 1773 communication links were achieved.

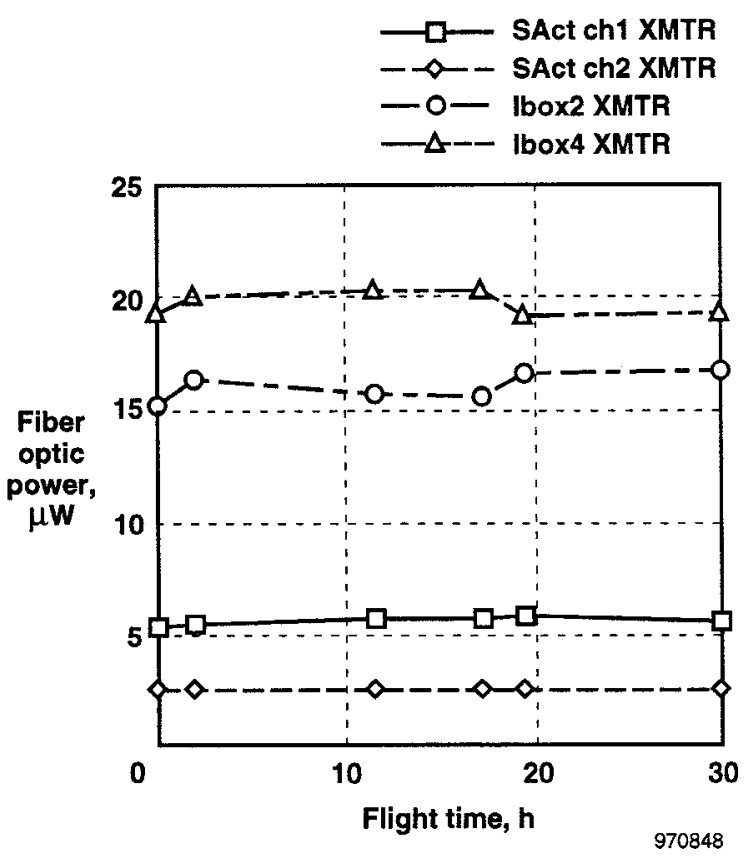

Figure 16. 1773 fiber optic transmitter power.

Figure 17 shows the attenuation spacing for each data link that was required in order to achieve the system optical power levels presented in figure 16. All of the data links show a similar trend. As shown in figure 17, the 1773 links required increasing attenuation spacing throughout the flight test program. The last two calibration data points also indicate that the optical power of the system began to stabilize and level out. This corresponds to approximately 20 flight hours. Since there were many potential causes, it is difficult to identify which contributing factors stabilized as a function of operational time. It is reasonable, however, to deduce that system components began to harden and become conditioned to thermal variations. This burn in period should be considered in developing system integration test plans. A potential improvement in this specific fiber optic system would be dynamic gaincontrol of the optical power such that sufficient power margin is maintained.

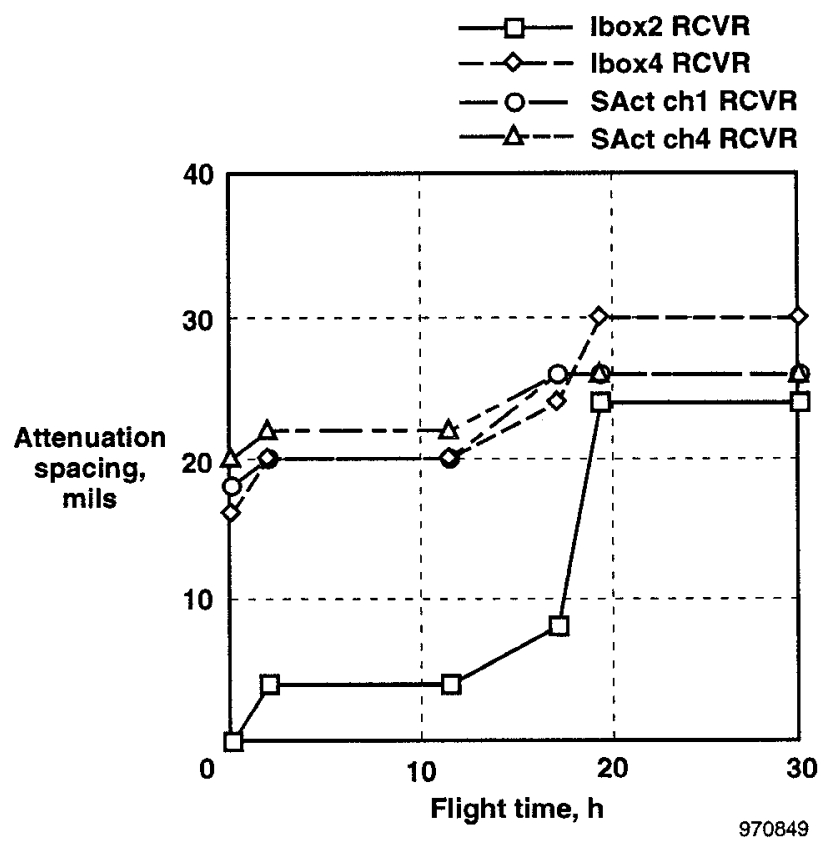

Figure 17. Required 1773 fiber optic attenuation.

\section{CONCLUSIONS AND RECOMMENDATIONS}

The smart actuator flight test program has demonstrated that in-flight local control, fault monitoring, and redundancy management of surface actuators is possible. As shown through flight test, the performance of the smart actuator was exceptional and compared very well to that of the standard F-18 aileron actuator.

Although the serial interface of the smart actuator could have been a conventional electrical interface, valuable fiber optic experience was gained through the use of 1773 communication links. System integration was greatly simplified, reducing both installation time and cable harness weight significantly. The fiber optic interface, however, complicated system integration tests. It was not possible to directly monitor the optical data stream without inducing communication faults. There is a need for in-line fiber optic inter-connect hardware with low insertion loss that will allow for such monitoring. 
Many contributing factors resulted in insufficient optical power margin. Because wide variations in optical transmitter output and receiver sensitivity existed, unique optical power levels for each data link were required in order to avoid detected waveform distortion and receiver saturation. In addition, environmental testing revealed significant thermal sensitivities among the various fiber optic components, and these sensitivities contributed to optical power level variations. Although a calibration procedure was developed to account for these variations, this procedure is not practical for aircraft. Therefore, tighter specification of fiber optic components is required in order to maintain adequate optical power levels. Specifically, thermal performance specifications of electro-optic components, preconditioned fiber optic cables, and improved cable terminations would significantly reduce optical system performance variations which are caused by environmental conditions. Dynamic control of optical transmitter output could improve system performance.

The smart actuator program identified critical areas of development for the general use of fiber optics in aerospace vehicle systems. These critical areas apply to a wide range of fiber optic applications, and will impact system operation and reliability unless particular attention and significant progress is made. Fiber optic terminations, cable harness composition, electro-optic components, and their variation to temperature will affect the operational margin of any fiber optic system. In order to reap the many potential benefits that fly-by-light technology offers, design considerations in these areas must be incorporated into future aerospace vehicle systems.

\section{REFERENCES}

[1] Deller, R.W., Second Generation Smart Actuator, SAE Technical Paper Series 932585, Sept. 27-30, 1993.

[2] Tran, George T., Mark D. Berry, Todd M. Turner, Edward P. Scannell, and R. Brad Cope, "Effects of High Power Microwaves on Smart Actuator Flight Control Circuits," Army Research Laboratory ARL-TR-1068, June 1996.

\section{[3] Military Standard-Digital Time Division Command/Response Multiplex Data Bus. MIL-STD-1553(DOD), Sept. 8, 1986.}

[4] Vayshenker, Igor, Xiaoyu Li, Darryl A. Keenan, and Thomas R. Scott, "Errors due to connectors in fiber power meters," National Institute of Standards and Technology Special Publication 905, pp. 49-52, Oct. 1996.

[5] Ott, Melanie; Jeannette Plante, Jack Shaw, and Margaret Ann Darrin-Garrison, Fiber Optic Cable Assemblies: Issues and Remedies, EEE Links, vol. 3 no. 1, pp. 1-5, Mar. 1997.

[6] Fiber Optic Terminations, Cable Assemblies and Installation, NASA-STD-8739.5, Aug. 1997. 